\title{
Desarrollo en la periferia de la periferia. Proyectos forestales y memorias de despojos en el Noroeste de Chubut, Patagonia, Argentina
}

\author{
MARÍA ALMA TOZZINI Y CAROLINA FLAVIA CRESPO
}

En este artículo se analizan, desde una perspectiva etnográfica, las particularidades de la implementación de proyectos de desarrollo en localidades pequeñas y alejadas de los centros de poder, como el Noroeste de la provincia de Chubut. A partir de las memorias de los afectados por estas políticas, los relatos de funcionarios y trabajadores, y la revisión de documentos estatales, examinamos las complejidades locales que supusieron. Precisamos de qué manera la acción de empresas forestales que operaron en la región, en el marco de estas políticas nacionales y provinciales de desarrollo, devinieron en condicionamientos severos de uso del espacio y sus recursos, y en algunos casos, en el despojo parcial o total de tierras sin titulación de campesinos e indígenas.

PALABRAS CLAVE: proyectos forestales de desarrollo, periferia, campesinos y mapuches, Noroeste de Chubut, Comarca Andina del Paralelo $42^{\circ}$, Patagonia argentina

Development on the Outermost Periphery. Forestry Projects and Memories of Dispossession in Northwest Chubut, Patagonia, Argentina

This article analyze, from an ethnographic perspective, the outcome of development projects on small and remote regions of Northwest Chubut. Based

María Alma ToZZINI

Consejo Nacional de Investigaciones Científicas y Técnicas, Universidad Nacional de Río Negro, Instituto de Investigaciones en

Diversidad Cultural y Procesos de Cambio, San Carlos de Bariloche, Río Negro, Argentina almatozzini75@gmail.com

Carolina Flavia Crespo

Consejo Nacional de Investigaciones Científicas y Técnicas, Instituto Nacional de Antropología y Pensamiento Latinoamericano, Universidad de Buenos Aires, Buenos Aires, Argentina carolcres@hotmail.com on the reports of those who were affected by these policies, the stories obtained from officials and workers in this context, as well as the review of state documents, we examined the complexities involved in this process at a local level. We aim to specify how the actions of forestry companies operating in this region at that time, within the framework of these national and provincial development policies, led to the severe conditions of use of land and its resources and, in some cases, to the partial or total dispossession of peasants and indigenous families from land with no title deed.

KEYWORDS: forestry development projects, the periphery, peasants and Mapuches, Northwest Chubut, Comarca Andina del Paralelo $42^{\circ}$ Region, Argentinian Patagonia 


\section{Introducción}

"Desarrollo" es la expansión económica adorándose

a sí misma (Lins Ribeiro, 2007: 173)

n 2008, como lo hicieron en 2005, varias organizaciones sociales y pobladores locales se dieron cita en el edificio de la escuela secundaria de El Hoyo, en el Noroeste de la provincia de Chubut, Comarca Andina del Paralelo 42 ${ }^{\circ}$, Patagonia argentina, para realizar otro "Foro de políticas públicas por el acceso a la tierra". La convocatoria tenía como propósito abrir un espacio en el que los pobladores cuyas tierras estuvieran atravesadas por conflictos o se vieran imposibilitados para acceder a ellas compartieran sus problemas y se organizaran. Entre las experiencias relatadas en esa oportunidad, se encuentran los recuerdos de Elba Pulgar Huentuquidel sobre las penurias que su familia ha vivido por su tierra en Puerto Patriada, un paraje rural de El Hoyo:

Sí, nosotros que somos de acá, de la zona, del barrial arriba. Ahí en el 78, más o menos, Bosques lo cerró. Mi abuelo tenía la casa de este lado y ellos cerraban con alambre, los de Bosques. Y mi abuela forzaba porque tenía las ovejas del otro lado, y las vacas. Venía Bosques, le volvía a cerrar. Y hace años, desde el año 78 que estamos luchando por nuestras tierras (entrevista con Elba Pulgar Huentuquidel, El Hoyo, 20 de septiembre de 2008).

Los relatos de los pobladores locales que vieron sus campos cercados por el ente provincial encargado de los bosques y la consecuente reducción de sus rodeos son una constante en la Comarca Andina. En su mayoría, remiten al periodo entre 1960 y 1980, en el que se implementaron políticas de desarrollo forestal impulsadas por la

$1 \quad$ La Comarca Andina del Paralelo $42^{\circ}$ es una región que comprende las localidades chubutenses de Lago Puelo, El Hoyo, Epuyén y El Maitén, y la localidad rionegrina de El Bolsón. En adelante, nos referiremos a ella como Comarca o Comarca Andina. 
Dirección General de Bosques y Parques del Chubut (DGByP) y dinamizadas principalmente por dos empresas, la Sociedad Anónima Forestal Epuyén (SAFE) y la Maderera Noroeste Sociedad Anónima (MaNOSA), que operaron en las localidades de Epuyén, El Hoyo y Lago Puelo.

En este artículo nos proponemos reconstruir, desde una perspectiva etnográfica, las complejidades locales que supusieron estas políticas de desarrollo. A partir de las memorias de quienes se vieron afectados de manera directa o indirecta por ellas, los relatos de funcionarios y trabajadores en ejercicio en ese contexto y la revisión de expedientes forestales, de tierras, judiciales, entre otros, analizamos las particularidades de la implementación de proyectos de desarrollo en localidades pequeñas y alejadas de los centros de poder y las instituciones, en especial en el marco de una provincia nóvel, como lo era Chubut cuando estos proyectos comenzaron. Examinamos la historia de las acciones de estas dos empresas forestales y nos enfocamos en las experiencias destacadas por los pobladores que han vivido en la zona o trabajaban en estos proyectos en aquel entonces, o ambos, y se han visto "vulnerabilizados" por estas iniciativas (Lins Ribeiro, 2007). Entendemos que ésta es una mirilla privilegiada para acceder a procesos que, si bien las trascienden, nos permiten reconstruir el contexto desde dos perspectivas. Por un lado, desde la manera en que la puesta en marcha de estas políticas influyó en el problema territorial que afecta a campesinos e indígenas de la Comarca Andina desde mucho tiempo atrás. Por el otro, desde la forma en que los proyectos de desarrollo entraman y enhebran lo público y lo privado, en ocasiones por medio de la figura de personas particulares. Apuntamos a precisar cómo el surgimiento y las acciones de estas empresas, en el marco de los proyectos de desarrollo implementados en zonas periféricas, devinieron en severos condicionamientos de uso del espacio y sus recursos, que en algunos casos significaron el despojo parcial o total de tierras de familias campesinas e indígenas.

\section{Algunos prolegómenos sobre las políticas forestales desarrolladas en el Noroeste de Chubut entre 1950 y 1970}

En 1949, la recién creada Administración Nacional de Bosques diseñó el Primer Plan de Ordenación Forestal de la nación. Este plan delimitaba el interés sobre determinadas superficies de bosque nativo e impulsaba la actividad forestal por medio de desgravaciones impositivas y créditos especiales. ${ }^{2}$ Casi diez años después, hacia 1960, se presentó otro plan de ordenamiento que promovía la reforestación con especies exóticas (Valtriani, 2008). Más que la defensa, protección, reproducción y ampliación del bosque por cuestiones ambientales o paisajísticas, el objetivo apuntaba a promover la producción de madera y la formación de una industria forestal (Mendes, 2010). El bosque importaba como recurso económico con valor de cambio en el mercado y las acciones institucionales tuvieron ese horizonte como motor (entrevista con ex responsable del Destacamento Epuyén de la DGByP, Esquel, 8 de marzo de 2016), incluso durante la década de 1970, cuando se creó el Instituto Forestal Nacional (IFONA). ${ }^{3}$

Si bien Valtriani (2008) y los ex funcionarios de la DGByP (entrevistas, Esquel, Chubut, diciembre de 2015 y marzo de 2016) señalan la ausencia de una política integral de desarrollo forestal nacional,

2 Las desgravaciones y créditos formaron parte de la Ley Nacional núm. 13273 de "Defensa de la riqueza forestal" (Congreso de la Nación Argentina, 1948). El Banco de la Nación y el Banco de Crédito Industrial eran las instituciones que otorgaban estos créditos. Sin embargo, según Danklmaier (2007), ni los créditos ni las desgravaciones impositivas resultaron tan atractivas como se esperaba.

3 En 1973, con la modificación del artículo 74 de la Ley Nacional núm. 13273 (Congreso de la Nación Argentina, 1948), se crea el IFONA, ente autárquico del Estado que se constituye en el organismo de aplicación de ésta ley. La entidad se descontinúa en sus funciones con el Decreto Ley de "desregulación pública” núm. 2284 (Subsecretaría de Bosques e Incendios de Chubut, 1991). 
las propuestas diseñadas se inscribían dentro de programas de desarrollo, cuyo propósito era impulsar el tránsito de formas de producción "tradicionales" a modelos productivos y de consumo "modernos", mediante la inversión estatal en sectores industriales considerados estratégicos. ${ }^{4}$

En esta época regía un paradigma de desarrollo esencialmente económico, asociado a un crecimiento y progreso de evolución lineal. Este paradigma entendía que sólo podía desafiarse la desigualdad y la pobreza por medio de la apropiación eficiente y económicamente rentable de recursos naturales, bajo un estilo de vida de tipo occidental (Gudynas, 2011). Bajo esta visión, las prácticas tradicionales se entendían como un obstáculo y debían ser reemplazadas por las que los países "desarrollados" occidentales ofrecían. Los debates se centraban en la distribución de los beneficios que traería el desarrollo, las asimetrías en las relaciones internacionales, la propiedad de los medios de producción, etc. Pero ciertas nociones en las que se basaban estas políticas, como "avance", "modernización" o "progreso", no se cuestionaban, tampoco el postulado sobre "la necesidad de aprovechar la riqueza ecológica de América Latina para nutrir ese crecimiento económico" (2011: 25).

En el marco de este paradigma y de los planes nacionales de ordenamiento del bosque, las recién creadas provincias de Neuquén, Río Negro y Chubut impulsaron en sus jurisdicciones una serie de políticas de desarrollo forestal. Entre las décadas de 1960 y 1970 promovieron acciones sobre los recursos boscosos de la cordillera, que tenían como propósito impulsar un sistema de producción alternativo a la ganadería ovina extensiva. Incentivaron la plantación de especies exóticas de rápido crecimiento provenientes del hemisferio norte - pinos oregon, ponderosa, radiata y murrayana-, que se superponían con el área de distribución del ciprés de la cordillera ${ }^{5} \mathrm{y}$ de otras especies nativas, sobre las que se operó la tala rasa a partir de la década de 1970.
En el caso de la provincia de Chubut, la mayor parte de las forestaciones realizadas entonces pertenecían a dos empresas que se expandieron en el Noroeste cordillerano: SAFE, y en menor medida, MaNOSA (Valtriani, 2008). ${ }^{6}$ Esta región, fronteriza con Chile, se había constituido como periférica respecto de las grandes inversiones del capital y también por la forma en que sus pobladores fueron visualizados por las agencias estatales. En su mayoría, vivían ahí pequeños campesinos, muchos de ellos indígenas no reconocidos, de muy escasos recursos, a quienes se negaba la regularización de sus espacios territoriales, lo que los colocaba en una situación de vulnerabilidad. Una serie de normativas de distinto alcance promovía esta condición, que a la par habilitaba este tipo de emprendimiento por parte de las agencias estatales provinciales. La flamante Constitución provincial de 1957, en su

$4 \quad$ Valtriani (2008) y los ex funcionarios de la DGByp (entrevistas, Esquel, Chubut, diciembre de 2015 y marzo de 2016) sostienen que no hubo una política forestal explícita en el marco de un plan nacional estratégico, sino que "en los últimos 50 años se han usado diferentes instrumentos económicos (aportes reintegrables y no reintegrables) y fiscales (desgravación impositiva, exención y estabilidad fiscal) de promoción para el fomento de las forestaciones. Estos instrumentos se fueron adaptando a las diferentes épocas y se diferenciaron en su monto por regiones o por parámetros técnicos forestales, como zona de implantación, especie, modalidad de plantación (cortina, macizo, secano o bajo riego)" (2008: 141).

5 La introducción de coníferas exóticas en la región andina de la Patagonia comienza mucho antes, en la década de 1930. Se domesticaron en viveros de la Administración de Parques Nacionales. Luego, en 1950, la Administración Nacional de Bosques, y más tarde el IFONA, instalaron viveros y plantaciones a gran escala en algunas zonas de Chubut (Valtriani, 2008).

6 Esto no quiere decir que otras empresas forestales no operaran en zonas muy cercanas. En Epuyén, además de SAFE, a comienzos de la década de 1970 se instala la Empresa Robles, S. A. (Provincia del Chubut, 1973; Gatti, 2005). Aunque fueron casos excepcionales, también se concedieron algunas parcelas a otros empresarios en zonas linderas a las concesiones que obtuvo Manosa. 
artículo 102, establecía que el bosque era de propiedad inalienable de la provincia y ésta tenía pleno dominio y jurisdicción sobre los recursos naturales de todo el territorio (Convención Constituyente, 1957). Además, dos normativas contribuían al ejercicio de ese dominio y jurisdicción, en particular en esta zona andina fronteriza. Por un lado, la Ley Nacional de Zonas de Seguridad de Fronteras núm. 15385 (Ministerio del Interior, 1944) denegaba la entrega de títulos a quienes fueran considerados de nacionalidad extranjera; entre ellos, muchos mapuches que ocupaban estos espacios, de quienes se consideraba sólo el lugar en el que habían sido enrolados en el ejército - en muchos casos, Chilesin tomar en cuenta su origen étnico. Por otro lado, el decreto núm. 2585, de 1961, prohibía otorgar la propiedad de la tierra a quienes tuvieran más de 30\% de bosque (Subsecretaría de Bosques e Incendios de Chubut, 1961). ${ }^{7}$ Ambas normas negaban a muchos pobladores de esta zona la titulación del espacio ocupado y a cambio otorgaban un permiso precario de ocupación que, como su nombre lo indica, los dejaba en una posición frágil ante posibles acechos sobre sus territorios y recursos.

\section{Las empresas "desarrolladoras". Entre el personalismo y la "consorciación"8}

Las empresas SAFE y MaNOSA intervinieron como "agentes o industrias del desarrollo" en localidades de la Comarca bajo características diferenciadas y trayectorias divergentes (Lins Ribeiro, 2007).

SAFE, de Ramón de Errasti, se instaló en Puerto Patriada — en la actualidad, localidad de El Hoyohacia 1960, en una antigua ocupación de 144 ha de una familia que no tenía título de propiedad y desarrollaba actividades ganaderas. ${ }^{9}$ De Errasti se ubicó ahí con el propósito de crear un establecimiento forestal exclusivo. Aunque no logró concretarlo, su interés era emplazar una planta industrial de aglomerado. De Errasti contaba con cierto capital gracias a un aserradero que poseía en Epuyén, y según algunos entrevistados, tenía vínculos con los poderes políticos de la época. Su actividad en la zona había empezado con el primer plan de ordenación forestal nacional, en el que había realizado una serie de cortas de bosque nativo entre 1951 y 1960 (Valtriani, 2008), pero hasta 1963 la provincia le concedió una gran cantidad de beneficios para la explotación de los recursos boscosos. Por un lado, le otorgó la explotación de una gran superficie de hectáreas de bosque en Puerto Patriada, en concesión por 30 años, con posibilidad de renovación por 30 años más, ${ }^{10}$ y la propiedad de la madera de esta reforestación. También le brindó apoyo financiero para crear una planta de fabricación de aglomerados y le cedió la concesión de las aguas de la laguna Las Mercedes para proveerse de electricidad para la planta industrial (Valtriani, 2008). En 1968 le renovó por cinco años más la reforestación del lugar. Ante la baja rentabilidad y la falta de cumplimiento en los apoyos provinciales que reclamaba la

7 Este decreto se modificó hacia 1975 (Valtriani, 2008); sin embargo, tuvo un gran impacto en la posterior pérdida de territorio de veranada -campos de altura- de muchos pobladores (véase la nota 16).

8 Tomamos este término de Lins Ribeiro (2007).

9 De Errasti adquirió los derechos del territorio antiguamente ocupado por la familia Monsalve. Mientras en algunos trabajos se sostiene que él compró ese espacio, pero nunca pudo escriturarlo por reparos de la provincia (Valtriani, 2008), los descendientes de Monsalve -quienes comenzaron un proceso de recuperación de su territorio en 2010, apelando a su identidad mapuche- sostienen que no hubo tal compra, sino que Monsalve fue cercado, le quemaron la casa, lo amenazaron y echaron a sus animales porque no quería vender (Comunidad Mapuche Quiñé Folil, 2012).

10 La extensión de la concesión difiere según los documentos consultados. En el dictamen núm. 93/1999, esa extensión era ambigua, pues se sostenía que abarcaba "una superficie de acuerdo a lo indicado en el plano oficial de la Administración Nacional de Bosques para el Cuartel lago Epuyén" (Subsecretaría de Bosques e Incendios de Chubut, 1999). 
empresa para la instalación de la fábrica de aglomerado, la provincia la incorporó a un proyecto de reequipamiento y adecuación industrial que promovía la producción de viviendas y productos de carpintería industrializados. A partir de 1973 y hasta 1976, la empresa y la DGByP se vieron inmersas en una serie de negociaciones. SAFE pidió nuevos proyectos de contratos, pero la provincia otorgó contratos a terceros sobre el área y le quitó la exclusividad. En 1979, se le otorgaron 858 ha más. Hacia 1983, la zona de explotación de la empresa se proclamó área turística y esto generó incompatibilidades con la producción forestal (Valtriani, 2008). Por diversos motivos, la empresa comenzó a tener problemas económicos y quebró. En 1999, se declararon extinguidas las concesiones, y en 2002, se dictaminó la caducidad de la adjudicación de las 144 ha de
Puerto Patriada. Muchos recuerdan la deuda nunca saldada de la empresa con los empleados, las frustradas iniciativas colectivas de reclamos, en especial la falta de pago de los aportes de seguridad social a varios de sus empleados a lo largo de todo su ciclo de funcionamiento.

Por su parte, MaNOSA no fue otra cosa que una agrupación de aserraderos familiares de baja escala - en su mayoría extranjeros, como sirio-libaneses, polacos, ucranianos o de primera generación argentina- que se encontraban en las localidades de Lago Puelo y El Hoyo. Se unificaron a comienzos de la década de 1970, bajo el decreto núm. 39/72 de la DGByP de Chubut (Provincia del Chubut, 1972), aunque algunos ex trabajadores sugieren que fue en respuesta a una presión ejercida por el Estado, que los amenazó con no permitirles seguir operando

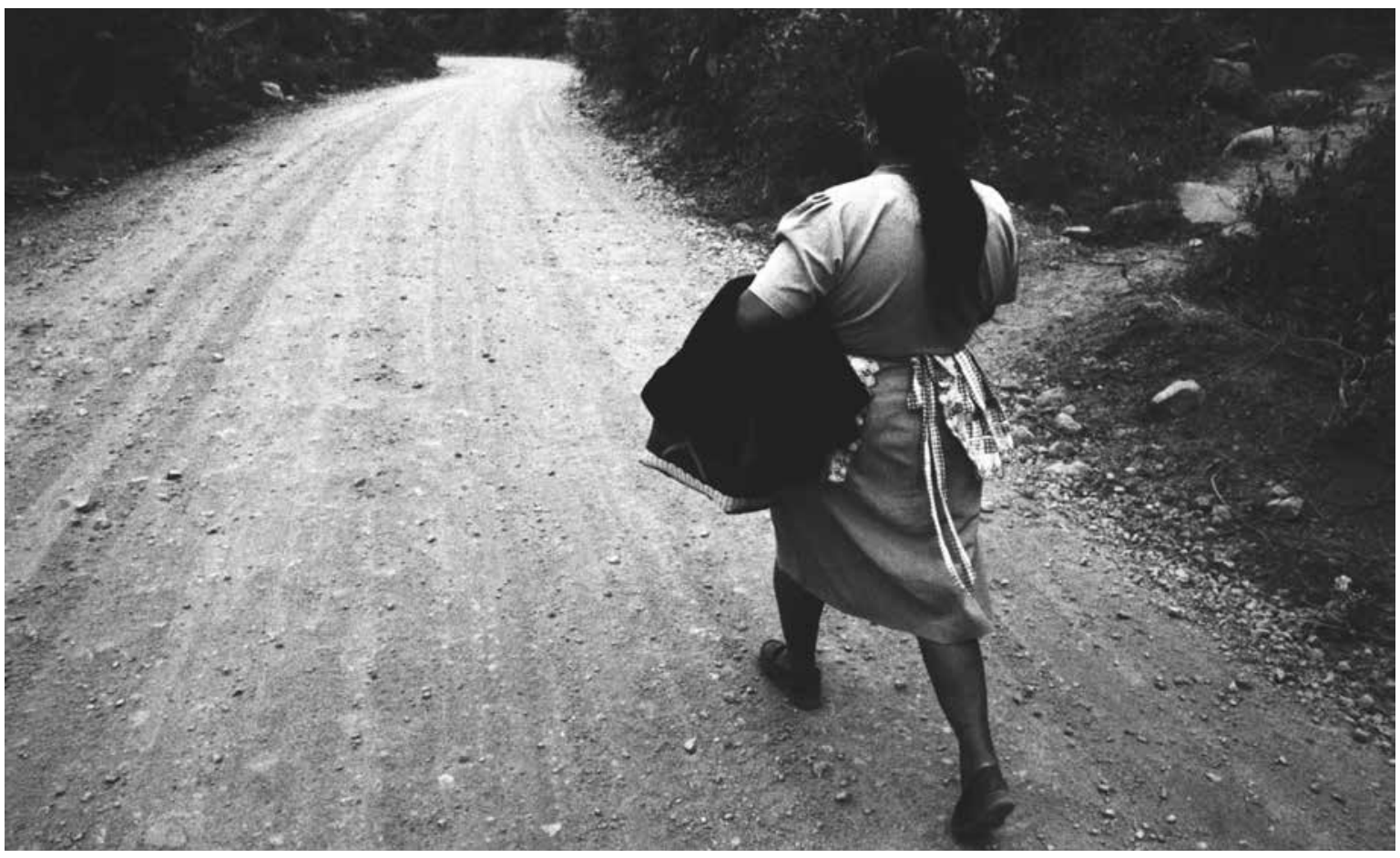

Ricardo Ramírez Arriola - "Cuando nos avisan en la noche que la paciente ya está en trabajo de parto, corremos a atenderla. Nos alumbramos con ocote por los caminos, para que todos se den cuenta, hasta los borrachos y los ladrones, que vamos a asistir un alumbramiento". San Pedro Pinula, Jalapa, Guatemala, 2000. 
en la zona si no concretaban la integración. Desde sus orígenes, MaNOSA fue pensada por el Estado provincial como una empresa forestal monopólica que incentivaría el desarrollo regional. Se buscaba una explotación "más eficiente" de los recursos, dado que, por su dimensión, los aserraderos resultaban antieconómicos y desperdiciaban materia prima (Provincia del Chubut, 1972). Un ex empleado de MaNOSA agrega que la idiosincrasia de sus dueños y la forma en que concebían "el negocio" frenaban las inversiones en maquinaria que les hubieran permitido una explotación con menor desaprovechamiento de recursos. ${ }^{11}$ De manera que el proyecto de unificarlos, según el Estado provincial, respondía a propiciar una explotación de características industriales que evitara el desperdicio. El objetivo era integrar la explotación de la materia prima con un secadero, un aserradero y la fabricación de carpintería de obra, con la instalación de un vivero que produjera las plantas necesarias para las forestaciones compensatorias. A diferencia de SAFE, su presidencia fue rotativa entre los dueños de los pequeños aserraderos, pero como parte del mismo paradigma de desarrollo bajo el que operó, la empresa se dedicó a deforestar extensas superficies de bosque nativo y reforestarlo con variedades de pino en las localidades de Lago Puelo y El Hoyo. ${ }^{12}$ El Estado le otorgó un crédito para instalar la planta industrial. Si bien el consorcio cumplió con su instalación, mejoró y elevó su productividad - en poco tiempo pasó de producir 500000 a 2000000 de plantas anuales en su vivero-, lo cierto es que siguió operando con la mentalidad individualista de una empresa pequeña. La falta de afinidad societaria condujo a permanentes pujas de poder internas, en las que cada parte buscaba lo mejor para "su" pequeño aserradero, lo que limitaba y afectaba la actividad. Según testimonios de ex funcionarios y trabajadores calificados, esta falta de acuerdos y de trabajo conjunto trajo aparejados "desmanejos" — mala administración- y ausencias severas de control en los cortes y las intervenciones en el medio boscoso objeto de explotación. Cortes clandestinos, desperdicios de rollizos a gran escala — que se bajaban, pero no se utilizaban-, robo de madera, etc., fueron dinámicas frecuentes, producto de esta suerte de individualismo societario. La empresa tuvo varios problemas, en particular de liquidez, ${ }^{13} \mathrm{y}$ su paquete accionario fue vendido a un empresario de la provincia. La planta funcionó hasta 1990 y arrastró hasta entonces diez años de decadencia. Buena parte de los pinos y de la tierra en la que éstos fueron plantados hasta hoy es una fuente de conflicto sin resolución.

Bourdieu (2006) sostiene que en las economías precapitalistas los empresarios son los que "hacen al capitalismo”. Ahora bien, Lins Ribeiro (2007)

11

Bandieri (1993) apunta una situación similar en la provincia de Neuquén, en la misma época: pequeños aserraderos que actuaban "con criterios extractivos, antes que productivos", y no se preocupaban por la fuente de la materia prima. Para Bandieri, esto era una estrategia que permitía desactivar con rapidez la poca inversión existente sin mayores pérdidas y virar hacia otra actividad relacionada - construcción en madera, por ejemplo-, en caso de que la tasa de ganancia se redujera mucho. Estas acciones condujeron a la provincia a obligar a los aserraderos a conformar una unidad productiva de características industriales.

12 En un principio, la superficie reservada para que manosA operara ascendía a 40000 ha. Según el decreto 39/72, comprendía "la superficie forestal existente en el área de Lago Puelo, Golondrinas y El Hoyo en el Departamento de Cushamen de esta Provincia" (Provincia del Chubut, 1972). Dados los problemas e incumplimientos que se suscitaron a lo largo de los años, esta superficie fue restringida a sólo 1897.59 ha y un nuevo contrato de concesión anexo (Provincia del Chubut, Poder Ejecutivo, 1991).

13 Uno de los entrevistados, ingeniero forestal, ex empleado de la empresa, señala que el comienzo de la decadencia de la empresa se relacionó con la Ley de Entidades Financieras núm. 21.526 (Presidencia de la Nación, 1977), que desincentivó la inversión industrial: "Martínez de Hoz saca la Ley de Entidades Financieras, se legisla la especulación por sobre la producción y cae la maderera de la noche a la mañana. Aparte de los problemas internos de la empresa, se le suma esto, y no dudaron en poner la plata en el banco más que en producir" (entrevista, Lago Puelo, junio de 2016). 
señala la relevancia que tienen en la lógica del desarrollo, por un lado, los "procesos de consorciación" - es decir, el encadenamiento de distintos grupos de poder que organizan nuevas entidades o "consorcios" para cumplir tareas económicas y administrativas-, pues son formas de reforzar las relaciones capitalistas de modo piramidal, en las que los niveles elevados ejercen su hegemonía sobre los niveles bajos; y advierte la importancia que adquieren, por el otro, las relaciones personales, pues habilitan coaliciones público-privadas ad hoc. En este caso, observamos algunos rasgos vinculados a estos planteamientos que nos permiten pensar en el desarrollo en la periferia. En el caso de SAFE, el personalismo de su dueño, que impulsa una forma novedosa de extracción de valor en un rubro "tradicional", como la explotación de la madera, y organiza de un modo particular el territorio de su empresa pero también sus lindes, es lo que, de alguna manera, torna "palpables" las aristas de una nueva organización económica en la región. ${ }^{14}$ Las palabras de su fundador resultan ilustrativas: "aprendimos que el primer cuento del bosque es que la riqueza no existe, hay que hacerla" (Ramón de Errasti, 1969, citado en Valtriani, 2008). En el caso de MaNOSA, este proceso y la forma de aprehenderlo se hace complejo, pues el Estado, por medio de esas instituciones que le permiten expandirse para tener presencia en la periferia de su territorio, es el que crea, con el consorcio, un actor empresarial para racionalizar, organizar y optimizar la extracción de valor de la explotación forestal que llevaban a cabo de manera dispersa varias pequeñas empresas. Si la empresa de De Errasti logró imponer un estilo de trabajo y organización de la producción por sí misma y funcionó como "organizadora” de los tiempos y dinámicas de algunas localidades, con MaNOSA ese proceso fue "posible" de manera compulsiva, y el Estado - con el proceso de consorciaciónfue quien diseñó, organizó y potenció, aun con las dificultades puntuales que esto acarreó, esa forma de extracción y concentración de valor.
Ahora bien, para concretar este proceso de extracción de valor se requirió operar antes otro cambio. Mastrangelo (2009) sostiene que los recursos no son naturales; más bien, se naturalizan en determinados procesos de enunciación. Así, al clasificar algo como natural, se actúa y se opera culturalmente en función de esa representación. Ambas empresas, y por medio de ellas los proyectos de desarrollo que las hicieron posibles, provocaron intensos cambios en el paisaje, que supusieron un proceso por el cual se resaltó la condición "natural" del recurso - el bosque nativo-, al tiempo que se descontextualizaba de sus condiciones sociales de existencia y uso.

\section{Entre condicionamientos y despojos: las acciones territoriales de las empresas y sus consecuencias para "los invisibles"}

La explotación del bosque a lo largo de estas décadas estuvo signada por dos modalidades de usufructo de sus recursos. Implementadas en etapas, estas modalidades marcaron de manera diferencial el vínculo con los pobladores locales y sus medios de vida, incluso supusieron consecuencias distintas en los territorios.

Según un ex empleado responsable del destacamento de Epuyén de la DGByP, antes de 1970, la explotación del recurso se basaba en el sistema de “entresaca”. Esto es, la DGByP otorgaba un permiso

14 Aún hacen falta estudios que permitan dimensionar los efectos de la explotación maderera de la inglesa Compañía de Tierras del Sud Argentino, S. A., en Puerto Patriada, hacia principios del siglo xx, sobre la organización económica y territorial de El Hoyo y Epuyén. Según Minieri (2006), desde la sede administrativa de la empresa en Leleque y Maitén, se organizaban las cortas que superaban de manera escandalosa lo permitido por el Estado nacional. Estos "límites traspasados" generaron complicadas negociaciones, no todas legales, entre funcionarios nacionales y directivos de la empresa. 
anual de entresaca a cada empresa maderera, lo que le permitía extraer un número determinado de plantas por hectárea. Se seleccionaban las mejores para ser maderadas y se dejaba el resto en pie. Sin embargo, a partir de 1970, con el cambio de dirección de la DGByp, comenzó una forma de explotación basada en el sistema de tala rasa. Este sistema de explotación forestal, que surge al mismo tiempo que se conforma MaNOSA y es adoptado también por SAFE, se basa en la quita completa del bosque nativo, no sólo de sus plantas maderables, para su reemplazo por especies exóticas de rápido crecimiento. Si el productor cumplía con la plantación estipulada, la DGByP le otorgaba otro permiso de desmonte completo el año siguiente.

La iniciativa de este tipo de explotación forestal se justificaba en tanto se preveía una mayor rentabilidad de estas plantaciones, comparada con la proveniente de la actividad ganadera ovina (Schlichter y Laclau, 1998); un incremento del empleo respecto del requerido para el pastoreo tradicional, y una rápida adquisición de recursos, comparada con el aprovechamiento del bosque nativo. Mientras un bosque de lenga o ciprés, especies nativas, madura a sus 80 años de edad, los pinos lo hacían aproximadamente en la mitad de ese lapso. Esto produjo tensiones con los pobladores locales, pues contravenía tanto sus formas tradicionales de subsistencia campesina como la tolerancia que hasta ese momento habían tenido ante la intervención de terceros en el medio boscoso que ocupaban. Ciertas tradiciones y seguridades que organizaban la vida campesina se vieron desgarradas por estas novedosas intervenciones estatales y privadas sobre su espacio (Tovillas, citado en Bourdieu, 2006). Si bien el sistema de entresaca había obligado a los pobladores sin títulos de propiedad a permitir el ingreso de otras personas a su tierra para hacer uso - bajo intereses y decisiones ajenas - de los mejores recursos del bosque nativo, no perdían sus espacios de pastoreo, y en ocasiones, estos espacios mejoraban, pues la entresaca posibilitaba el ingreso de más luz solar.
El corte indiscriminado de las mejores plantas de ciprés produjo cambios importantes en el ambiente a largo plazo. No obstante, la situación se agravó a partir de la puesta en marcha del sistema de deslindes de parcelas para la tala rasa, que en Puerto Patriada se combinó con la clasificación y ordenamiento del espacio como Reserva Forestal Cuartel Lago Epuyén en 1964. ${ }^{15}$ Esto no sólo modificó el paisaje local de manera radical, sino que introdujo cambios abruptos y produjo problemas severos para el poblador, que devinieron en su empobrecimiento. En efecto, las hectáreas otorgadas por la provincia a estas empresas con propósitos de explotación forestal eran en su mayoría tierras ocupadas por pequeños campesinos y mapuches que habían logrado obtener un permiso precario de ocupación sobre el espacio, pero nunca su titulación. Esto habilitaba a las dos empresas madereras, secundadas por la provincia, para cercar áreas de desforestación y reforestación con alambrado, y a excluir al poblador del uso para el pastoreo. Esta exclusión continúa hasta hoy, producto de la acidez generada en el suelo por el monocultivo de pinos, que inhibe el crecimiento de pasturas.

15

La Reserva Forestal Cuartel Lago Epuyén comprendía casi 20000 ha boscosas. Según se afirma en el decreto núm. 527/64 para su creación, la reserva surgía con el propósito de "proteger" la zona a causa de los incendios forestales intencionales sucesivos, ocurridos en 1944, 1960 y 1963, que habían destruido 70\% de la flora nativa (Subsecretaría de Bosques e Incendios de Chubut, 1964). El plan de "recuperación" del área involucraba su "clausura mediante la construcción de alambrados, el control de pastoreo de la ganadería, el aprovechamiento racional de sus maderas, trabajos culturales y demás estudios silvícolas para mejor y más ordenado aprovechamiento de esa masa forestal" (Subsecretaría de Bosques e Incendios de Chubut, 1965). Así, la creación de la reserva en Puerto Patriada ya había modificado el uso de los recursos del espacio. No obstante, los incendios no se han interrumpido desde entonces y las políticas forestales de estas décadas y el sobrepastoreo contribuyeron a afectar aún más la región. 
Las familias, cuyo mayor capital eran sus animales, se vieron obligadas a venderlos o trasladarlos a espacios cercanos, con lo que perdieron gran parte de su patrimonio y riqueza, pues algunos se extraviaban, morían o eran robados.

El sistema de tala rasa, que provocó serias pérdidas en las posibilidades de reproducción de los sujetos, sumado a los contratos de concesión otorgados a los empresarios forestales, tornó desesperante el panorama del poblador. Ante la carencia de títulos de propiedad, los empresarios detentaban un contrato de concesión en el cual una gran cantidad de hectáreas del bosque de las localidades estaban sujetas a explotación. Es decir, si bien la DGByP otorgaba permisos anuales para tala rasa y reforestación, lo cierto es que el contrato de concesión daba vía libre a MaNOSA para poner bajo su ámbito de operación la masa forestal comprendida en los lotes allí detallados que, como apuntamos, abarcaba prácticamente toda la masa forestal aprovechable de esas localidades. De esta operación podían defenderse mejor quienes habían logrado tener títulos de al menos una parte de las tierras comprendidas en sus precarios permisos originales de ocupación: ${ }^{16}$

Es que ellos iban con el contrato de concesión donde estaba todo el territorio, todos estábamos ahí adentro, los convencían de que eso era de ellos, de la Maderera [MaNOSA] y arreglan con el poblador (entrevista con ex empleado de MaNOSA, Lago Puelo, junio de 2016) [las cursivas son nuestras].

Acá, cuando yo trabajaba, ¿sabe qué? El martillo de Bosques [herramienta con la cual la institución marcaba la madera para talar] se le dejaba a los empresarios (entrevista con DP, ex trabajador de SAFE y reclamante de su territorio, El Hoyo, 4 de diciembre de 2014).

La exclusión se justificaba con base en un aprovechamiento "racional", industrial y moderno del bosque versus las formas tradicionales que, como sugeríamos, se entendían como obstáculos para el desarrollo. Los dueños de estos aserraderos fueron apodados los "industriales/empresarios" por parte de los pobladores, quienes en sus recuerdos suelen vincular su poder y sus acciones a lo que en efecto los empobreció, y en algunos casos, los obligó a dejar el campo para asegurar su reproducción. ${ }^{17}$

El pesar era vivido por el poblador, era un desgarro, ellos tenían sus animales, las plantas pasaron a ser más importantes (entrevista con ex empleado de Manosa, Lago Puelo, junio de 2016).

Y sería claro, trabajaría con el Estado, con provincia, sería que nadie lo paraba, ¿no? Porque ellos venían y hacían y deshacían. Después empezaron a meter los pinos, ¿vio? Y acá lo engañaron, dijeron que ellos sacaban la madera nomás. Al finado Pulgar le dijeron que ellos sacaban la madera y quedaba la tierra. Pero ya después empezaron a alambrar, ya después pasaron un alambre, agarraron todo eso para allá (entrevista con VL, ex trabajador de SAFE y reclamante de territorio, El Hoyo, 13 de diciembre de 2013).

Aunque a priori estos proyectos no parecían unidos a mecanismos de despojo, el trabajo de campo nos

Algunas familias consiguieron titular sus campos de invernada, los más bajos, en los que pastaban sus animales en invierno, pero no los campos altos con bosque nativo, utilizados en verano. Esto tuvo como consecuencia que, aun habiendo titulado parte de la tierra, al no tener seguridad sobre toda la superficie, no pudieran sostener el ciclo completo de la ganadería.

17 Debe tenerse en cuenta que en esta zona la tierra apta para las pasturas de los animales es poca en relación con la superficie total. En el caso de muchos pobladores, parte de la tierra ocupada es muy escarpada y sólo se hacen travesías por la montaña para llevar a los animales a la veranada. Además, en este débil equilibrio, y para asegurar el ciclo de crianza, deben quedar tierras para ambas temporadas: invernada y veranada. 


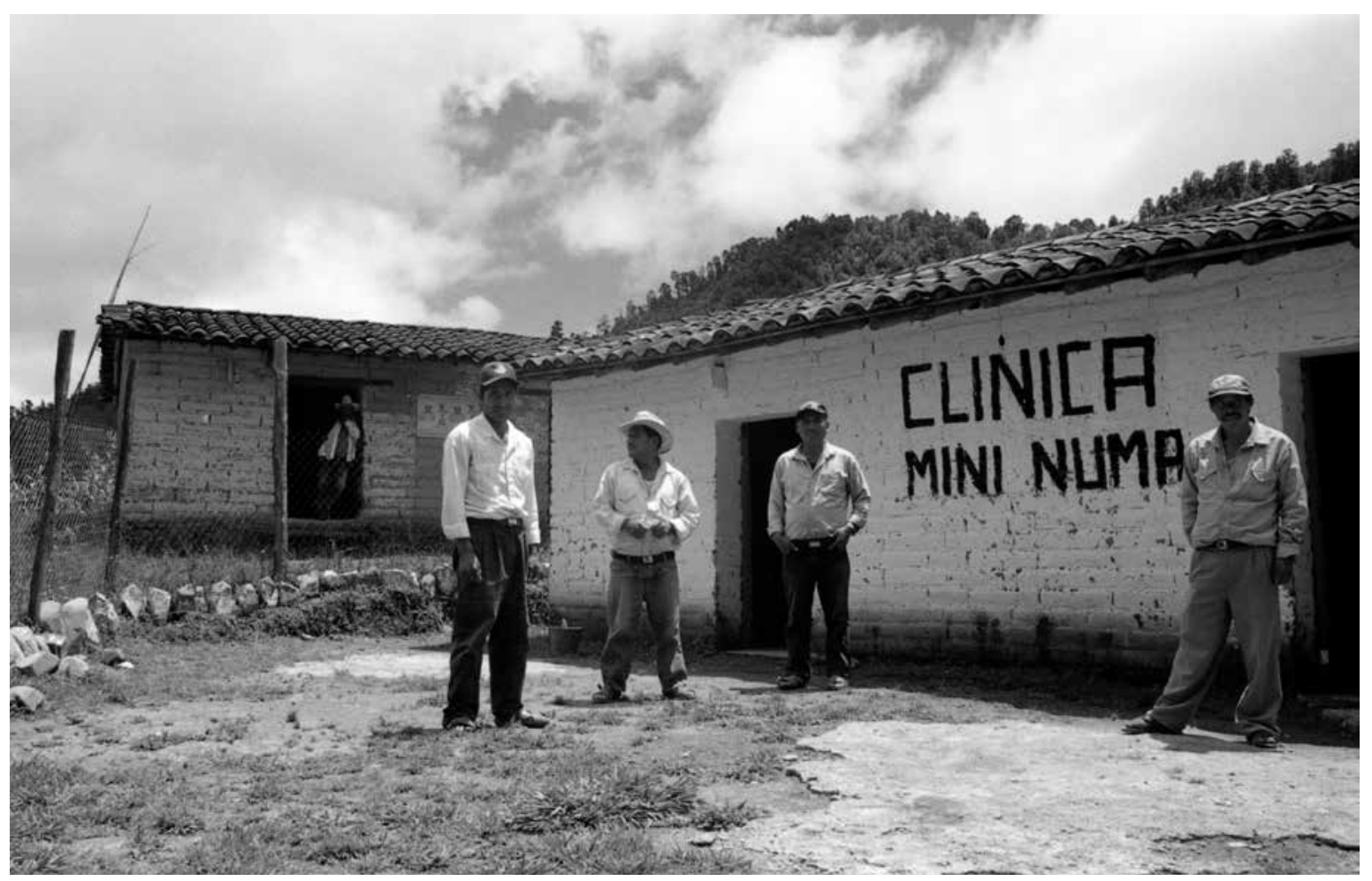

PROMETEO Lucero - Indígenas tu'un savi -mixtecos- lograron construir una clínica en la población de Mini Numa, después de interponer un amparo legal que obligara al gobierno estatal a atender a la población, 2008.

ha hecho comprender de qué forma la generación de empleo local que supuso este tipo de emprendimiento en la región se encuentra ligada a procesos de desposesión. Si como ilustra Bourdieu (2006), en su lúcido trabajo sobre Argelia, conviven durante cierto tiempo disposiciones e ideologías económicas que pertenecen a distintas estructuras económicas, estimamos que en estos casos la generación de empleo, la propagación de la ideología hegemónica de desarrollo imperante de entonces y una serie de engaños que los pobladores suelen destacar fueron los dispositivos que permitieron, en muchas ocasiones, la dilación de formas de conciencia ante los efectos más nocivos de la nueva y masiva manera de intervención del bosque.

Las entrevistas que mantuvimos sobre el tema, la investigación de Valtriani (2008) sobre modelos de desarrollo forestal en Chubut, así como su análisis sobre lo sucedido en el área, señalan la alta tasa de empleo de estas industrias, ya sea de manera directa - permanente o estacionalo indirecta. Valtriani (2008) apunta que SAFE empleó a más de 150 trabajadores de planta y MaNOSA a 300. A esto debemos sumarle la cantidad de jornaleros que trabajaban "en negro", de manera estacional, y el empleo indirecto que la presencia de estas fuentes de trabajo producía. ${ }^{18}$

18 Según el Instituto Nacional de Tecnología Agropecuaria en 1991 la población total de El Hoyo era de 1605 personas; la de Lago Puelo, de 2463, y la de Epuyén, de 1196. Estos datos evidencian la gravitación que tuvieron ambas empresas en las economías familiares de entonces, cuya población era aún más reducida (Sipan, s. f.). 
La generación de empleo a gran escala era algo desconocido para la zona. A la par, para muchos se trataba de la única fuente de trabajo cercana a su hogar y a la que podían acceder dado su bajo nivel de instrucción. Si bien suponía tareas muy pesadas y duras, incluso en las que se corrían ciertos riesgos físicos, no implicaba trasladarse lejos de la familia durante periodos prolongados, como en otros trabajos:

Tenías que saber trabajar en la cordillera. Saber pelear con los palos. Yo le tenía miedo a trabajar con las piedras porque se quedaban los palos. Se atrancaban porque los voltaban [sic] y quedaban cruzados. ¡Era muy duro! [...] Había poco trabajo en los años 70 y era la única empresa que había en ese tiempo (entrevista con PI, ex trabajador de MaNOSA y SAFE, Lago Puelo, 10 de marzo de 2015).

No había otra cosa, ésa era la empresa que había. Todos estábamos contentos. Ni siquiera sospechábamos que íbamos a quedar sin nada (entrevista con DP, ex trabajador de SAFE y reclamante de su territorio, El Hoyo, 4 de diciembre de 2014).

Asimismo, algunos visualizaban ciertas tareas como una extensión de las que estaban habituados a realizar en el monte. Las actividades de raleo y limpieza no eran ajenas a la vida campesina, más allá de que la actividad principal fuera la ganadería. Limpiar para reducir el riesgo de incendio y para acopiar leña, y mejorar las picadas para los animales eran tareas emprendidas por muchos en la zona. La nueva estructura de acumulación capitalista logró imponerse sin producir, en un principio, resistencias severas, pues el trabajo asalariado se acopló y superpuso a un hábito que, con diferencial acento, intensidad y sentido, algunos pobladores tenían, lo que propició una suerte de amortiguación de sus efectos adversos.

Como lo expresan en algunos relatos, la semejanza relativa con algunas actividades realizadas en el campo, y en especial la importancia que tuvo por ser la única fuente de ingreso cercano en contextos de escasez de recursos, fueron algunos de los motivos por los cuales las familias, que fueron perdiendo parte de su territorio de pastura, tardaron un tiempo en sentir la gravedad de esta reducción. A pesar de que hombres, mujeres y niños ${ }^{19}$ de las mismas familias a quienes cercaron sus espacios vitales y sus posibilidades de subsistencia recuerdan haber recibido un magro ingreso, a veces combinado con pago en especie por parte de SAFE, la menor productividad doméstica no se hizo sentir de manera acuciante en un primer momento.

A estos mecanismos se sumaba la dificultad para reclamar a las instituciones, sea por el poder que tenían los industriales como por la lejanía geográfica en la que estaban los espacios de reclamo. En el caso de SAFE, se agregaban las relaciones de tipo paternalista que, según algunos testimonios, Ramón de Errasti mantenía con los trabajadores, así como los engaños en los que recuerdan haber estado envueltos muchos pobladores por parte de ambas empresas:

Entonces le dice [De Errasti]: "Pulgar, ¿por qué no me das permiso para sacar la madera?”. Entonces el abuelo le dice: "si querés, llevate toda la madera, pero te voy a pedir que me dejes el campo cerrado y limpio para mis vacas". Cuando el abuelo le da el aval, este... lo primero que hacen fue hacer un camino de alambrada allá, que es por todos los cerros, quemaron todos los cercos, lo primero que hicieron. Entonces empezamos a cortar, empezamos a cortar digo, porque yo también colaboré con eso sin saberlo (entrevista con DP, ex trabajador de SAFE y reclamante de su territorio, El Hoyo, 4 de diciembre de 2014).

Porque MaNOSA, como ser, los de Maderera, plantaron pinos. Que fueron con mentiras primero,

19 En el caso de manosa, el vivero empleaba mujeres en su mayoría. En SAFE, según relatos de ex trabajadores, muchos trabajadores del vivero eran menores de edad. 
porque yo me acuerdo. Llegaron los del bosque: "Don Domingo - le dicen - venimos a esto, a esto”. “¡Ah! ¿Qué?”. "Queremos sacar la madera, porque para esto es la madera. Y pero le vamos a traer pinos”, dice. Le dice: “¿qué es pino?”. "Pino - dice- que es una madera mejor. Y en tantos años usted llega a [...] tiene una madera linda y mejor que el ciprés y el coihue y todo". Y dice: "crece muy rápido". Y le dice: "ah, sí, pero esos pinos van a ser de ustedes porque nosotros ahora, este, sacamos la madera, le sacamos el bosque, ¿vio?, los cipreses, el coihue, los talamos". "Bueno —dice él一, bueno, sí, bueno, saquen la madera”. Y ahí se metieron como... Claro, se lo llevaron todo a cambio de los pinos, ¿vio? [...] Como le pasó a la gente de El Hoyo [...], a todos le hacían el mismo baile, le presentaban el mismo plato. Y decía: "pero usted va a tener que sacar los animales porque los animales... van a poner los pinos ¿vio?” [...]. Los sacaron para que ellos saquen toda la madera y se la lleven, la vendan y pongan pino. Y ahora, ellos son los dueños de los pinos [...], de los pinos y de la tierra [ríe con ironía]. Era un daño, un daño moral a todos. No es que diga usted, yo hice daño a un solo poblador, nos hicieron daño totalmente a toda la zona [...], gente nativa (entrevista con VC, ex trabajador de MaNOSA y reclamante de su territorio, Lago Puelo, 7 de abril de 2009).

Como sugiere Gatti respecto a la empresa forestal del paraje El Coihue de Epuyén, estos emprendimientos forestales lograban obtener mediante un mismo movimiento los recursos de la tierra y "la propia mano de obra necesaria para su explotación a través del despojo de los campesinos" (2005: 11). No obstante, a pesar de todo, algunos recuerdan que ciertos pobladores ofrecieron resistencia a estos avances de las dos madereras. Lo hicieron cada uno a su medida y sus posibilidades: corrían alambrados, impedían el ingreso de "los industriales", metían a sus animales en los espacios plantados:
Hubo resistencia, sí, le mandaban los animales adentro de las forestaciones (entrevista con EB, ex trabajador de MaNOSA, Lago Puelo, junio de 2016).

Ponían alambre. Y mi abuela iba y cortaba los alambres. Iban ellos, los de Bosques, y otra vez le metían los alambres. Los de Bosques, Errasti se llamaba. Porque ellos querían agarrar para sembrar pino (entrevista con EP, reclamante de su territorio, El Hoyo, 11 de diciembre de 2013).

Y Bosques iba como policía. Como eran los dueños de la madera, decían: "yo voy a hacer esto y vamos a voltearlo allá”. Total, ellos llenaban el bolsillo, los pobladores quedaban en la calle y a ellos no les importaba que una familia muera o muriera un viejo. Le daba lo mismo. Así que fueron, y ahí, que dice M: "no, acá no se metan”, dice. "¿Por qué?” "Porque esto es ya es mío, y es propiedad". "No — le dicen—, venimos a esto". "No se metan - le dice-, si ustedes se meten lo...". Y dice: "como siempre hay... Uno que anda de más, sobre esto...”, agarró y se metió. Pasó el alambrado y se metió en el campo de M. Y m ya le había dicho que no se meta. Así donde se metió, lo agarró a huascasos. Tenía una revólver, que le dio una paliza adentro que... Así que los otros se defendieron. Después la trajeron a la policía y al médico de El Hoyo, que lo cure. iNo! Tenía unos... Después a M le trajeron, pero como [...] era como un atropello de domicilio, así que no le hicieron nada. Y ése es el único lugar que quedó, que no se metió MaNOSA (entrevista con VC, ex trabajador de MaNOSA y reclamante de su territorio, Lago Puelo, 7 de abril de 2009).

Pero también hubo ciertos rechazos de algunos pobladores sobre la tala innecesaria que se practicaba. Un ex trabajador de MaNOSA recuerda haber visto 5000 rollizos de coihue volteados en la tierra del poblador Alfredo Cárdenas, al oeste del río Azul, en Lago Puelo, que quedaron abandonados porque no 
podían bajarse desde la altura en la que habían sido talados. Según él, “Alfredo la peleó con Maderera [MaNOSA] pero no pudo parar el daño" (entrevista con ex empleado de MaNosA, Lago Puelo, junio de 2016). El relato resulta significativo, pues el consorcio conformado para paliar las formas precarias de producción de los aserraderos, que derivaban en desaprovechamiento del recurso, no evitaban el desperdicio. Producto del "desmanejo" e individualismo de sus socios, el acceso a grandes superficies boscosas y el nulo control estatal, el desaprovechamiento y el derroche se potenciaron.

Con el correr de los años, los pinos se convirtieron en una plaga que desertificó el suelo, y según algunos relatos de pobladores locales, modificó las condiciones climáticas hacia temperaturas más secas. En los últimos años, funcionarios de las instituciones relacionadas con el bosque se lamentan de los efectos nocivos introducidos por el pino y prevalece en el discurso oficial la importancia de preservar las especies nativas, en particular el ciprés. Algunos pobladores reflexionan sobre esa época y comparan la codicia de los empresarios forestales de entonces con la codicia inmobiliaria del presente. Señalan a ambas como severas formas de intervención del territorio en pos de un negocio para sectores concentrados del capital. En este contexto, y en el marco de las reflexiones sobre aquellas experiencias y sucesos vividos, el pino, lejos de ser considerado un "recurso natural" suele ser definido por los pobladores nativos como un "mugrerío".

\section{A modo de cierre}

La visión ontológica que distinguió en esa época a los países desarrollados de otros que se encontraban subdesarrollados y debían alcanzar el desarrollo, se expandió en el imaginario social en el interior de estos últimos, que también dividieron espacios territoriales y sujetos para replicar estos imaginarios y categorías. Esto sucedió en Argentina y en la región patagónica, en la que ciertas áreas se diferenciaron, en tanto "atrasadas", para promover ahí el desarrollo. En algunas, lo hicieron con proyectos de gran envergadura. En otras, como en el caso de la región del Noroeste cordillerano, se montaron emprendimientos de dimensiones menores, pero no por ello sin implicaciones a corto y largo plazo.

Diversos motivos nos orientan a pensar en las acciones emprendidas en el Noroeste cordillerano de Chubut como políticas e ideas de desarrollo en la periferia de la periferia. Por un lado, porque se trataba de espacios fronterizos alejados de las instituciones, no sólo nacionales sino también provinciales, y suponían poco interés para el capital hasta entonces interesado, en todo caso, en la agricultura y ganadería a gran escala, como la desarrollada en otras zonas del país, o la industrialización vinculada a determinados rubros. Por otro, porque, en comparación con otros proyectos impulsados en Argentina, las acciones de desarrollo desplegadas contribuyeron de manera menguada en términos económicos. Por último, porque se caracterizó por reproducir la inclusión subordinada y exclusión de la población, que desde la conformación del Estado-nación había sido incorporada a la periferia bajo derechos diferenciados y desiguales respecto del resto de la ciudadanía, y cuyas condiciones de vida eran precarias.

Hacia la década de 1970, mientras estos proyectos de desarrollo entraban en escena, pocos estudiosos ponían en entredicho tanto sus bases de pensamiento como sus posibles implicaciones. Furtado sostenía que la idea de que "los pueblos pobres podrán algún día disfrutar de las formas de vida de los actuales pueblos ricos" era utilizada para "movilizar a los pueblos de la periferia y llevarlos a aceptar enormes sacrificios" y formas de dependencia, socavar prácticas culturales diferentes, etc. (Furtado, 1975, citado en Gudynas, 2011). Junto a estos cuestionamientos provenientes de las teorías de la dependencia, otros elaboraron un informe, en 1972, 
en el que planteaban la existencia de límites - en especial ecológicos - a la idea de un crecimiento perpetuo (Meadows et al., 1972, citado en Gudynas, 2011). De ahí en adelante, las reflexiones y críticas respecto al desarrollo y las concepciones que secundaban estos proyectos siguieron su curso por diversos senderos teórico-metodológicos dentro de la academia (Escobar, 2005; Restrepo, 2006; Rist, 2002). En la cordillera chubutense, como se pudo apreciar en este análisis, los "periféricos de la periferia", los pequeños campesinos, muchos de los cuales se reconocerían y organizarían en los últimos años como comunidades indígenas reclamantes de sus territorios expropiados, fueron movilizados para intervenir en estas políticas con la esperanza de mejorar sus condiciones de vida. Las posiciones y cuestionamientos que mantuvieron fueron divergentes y en ocasiones era difícil distinguir entre sujetos que se resistieron y sujetos que acataron con pasividad estos emprendimientos. Algunos ensayaron comportamientos combinados, recurrieron en ciertos momentos a tácticas que desafiaran las jerarquías de poder prevalentes, incluso siguieron reclamando con intermitencias hasta la actualidad. Otros hicieron sus denuncias más tarde y unos más no denunciaron o bien guardaron sus experiencias entre las que relatan dentro del hogar. Pero para la mayoría, a largo plazo, estas experiencias se materializaron de manera indeleble, no sólo en el paisaje local sino en su propia trayectoria, su subjetividad y sus luchas.

En años recientes, los reiterados encuentros en los que se comparten historias de experiencias similares en la región permitieron desplazar la historia de estos proyectos forestales de meras historias ambientales o productivas a complejas experiencias con las cuales pueden explicarse - y ahora comprenderse con detalle- sus historias de despojo y sufrimiento. Esto ha significado, en palabras de Bourdieu (2006), una suerte de posibilidad de "reapropiación del porvenir" para muchos pobladores. D

\section{Bibliografía}

Bandieri, Susana, 1993, “Actividades económicas y modalidades de asentamiento”, en Susana Bandieri, Orietta Favaro y Martha Morinelli, Plus Ultra, Buenos Aires, pp. 147-261.

Bourdieu, Pierre, 2006, Argelia 60. Estructuras económicas y estructuras temporales, Siglo XXI Editores, Buenos Aires.

Comunidad Mapuche Quiñé Folil-Puerto Patriada, 2012, "Reseña histórica de la Comunidad Mapuche Francisco Monsalve, Quiñé folil (primera raíz) de Puerto Patriada. El Hoyo, Provincia del Chubut”. Disponible en línea: <http://lof-monsalve.blogspot.mx/2012/01/resena-historica-de-la-comunidad.html>

Congreso de la Nación Argentina, 1948, Ley Nacional núm. 13273 de "Defensa de la riqueza forestal”, 6 de septiembre. Disponible en línea: <http://servicios.infoleg.gob.ar/infoleglnternet/verNorma.do?id=30713>.

Convención Constituyente, 1957, Constitución provincial del año 1957, 11 de octubre. Disponible en línea: <https://www.juschubut.gov.ar/images/normativa/constituciones/const_57/57con1.htm>

DankImaier, Christine, 2007, "La actividad forestal”, en Proyectos federales de innovación productiva PFIP 2004-1. Modelos de desarrollo forestal para la diversificación de los sistemas agrarios del Noroeste del Chubut, diagnóstico social, Centro de Investigación y Extensión Forestal Andino Patagónico, Esquel.

Escobar, Arturo, 2005, “El 'postdesarrollo' como concepto y práctica social”, en Daniel Mato (coord.), Políticas de economía, ambiente y sociedad en tiempos de globalización, Universidad Central de Venezuela-Facultad de Ciencias Económicas y Sociales, Caracas.

Gatti, Pablo, 2005, "De la sociedad campesina a la supeditación capitalista. ¿Ciudadanos o pobladores? Transformación socioambiental del Paraje El Coihue en la década de 1970", trabajo final del Seminario de Historia Regional, Carrera de Historia-Facultad de HumanidadesUniversidad Nacional del Comahue-Centro Regional Universitario Bariloche, Neuquén.

Gudynas, Eduardo, 2011, “Debates sobre el desarrollo y sus alternativas en América Latina: una breve guía heterodoxa”, en Miriam Lang y Dunia Mokrani (eds.), Más allá del desarrollo. Grupo Permanente de Trabajo sobre Alternativas al Desarrollo, Fundación Rosa Luxemburgo/Abya Yala, Quito, pp. 21-54. 
Lins Ribeiro, Gustavo, 2007, “Poder, redes e ideología en el campo del desarrollo”, en Tabula Rasa, núm. 6, pp. 173-193.

Mastrangelo, Andrea, 2009, "Análisis del concepto de recursos naturales en dos estudios de caso en Argentina", en Ambiente \& Sociedade, vol. 13, núm. 2, pp. 341-355.

Mendes, José María, 2010, Sociedades del bosque. Espacio social, complejidad ambiental y perspectiva histórica en la Patagonia andina durante los siglos Xix y Xx, tesis de maestría en teoría y metodología de las ciencias sociales, Consejo Latinoamericano de Ciencias Sociales.

Minieri, Ramón, 2006, Ese ajeno sur, Fondo Editorial Rionegrino, Viedma.

Ministerio del Interior, 1944, Decreto Ley 15385/19944, creación de zonas de seguridad, 13 de junio. Disponible en línea: <http://mininterior. gov.ar/fronteras/pdf/decreto-ley-15385-44.pdf>.

Presidencia de la Nación, 1977, Ley 21.526, 14 de febrero. Disponible en línea: <http://servicios.infoleg.gob.ar/infoleglnternet/anexos/1500019999/16071/texact.htm>.

Provincia del Chubut, 1972, "Decreto 39/72", en Boletín Oficial, año 16, núm. 1460, 10 de febrero.

-, 1973, Decreto núm. 468/73, 14 de marzo, Subsecretaría de Bosques e Incendios de Chubut.

, 1991, "Contrato de Concesión de Aprovechamiento Forestal. Dirección Provincial de Bosques y Parques y Maderera del Noroeste,

S. A.", 31 de octubre. Archivo privado.

Provincia del Chubut, Poder Ejecutivo, 1991, "Decreto 1697/91”, 17 de octubre.

Provincia del Chubut, Ministerio de Economía, Servicios y Obras públicas, 1972, "Contrato de Concesión de Aprovechamiento Forestal entre Dirección Provincial de Bosques y Parques y Maderera del Noroeste, S. A.", 19 de enero.

Restrepo, Eduardo, 2006, "Teoría social, antropología y desarrollo: a propósito de narrativas y gráficas de Arturo Escobar", en Boletín de Antropología, vol. 20, núm. 37, pp. 307-326.

Rist, Gilbert, 2002, El desarrollo: historia de una creencia occidental, Libros de la Catarata, Madrid.

Schlichter, Tomás y Pablo Laclau, 1998, "Ecotono estepa-bosque y plantaciones forestales en la Patagonia norte”, en Ecología Austral, vol. 8 , núm. 2, pp. 285-296.

Sistema de Información Patagonia Norte (Sipan), s. f., “Cantidad de habitantes de la Comarca Andina del Paralelo 42”. Disponible en línea: <http://sipan.inta.gob.ar/productos/ssd/vc/comarca/ig/cantidad_de_habitantes.htm>. Consultado el 29 de noviembre de 2016.

Subsecretaría de Bosques e Incendios de Chubut, 1961, Decreto núm. 2585, 7 de julio.

— 1964, Decreto núm. 527/64, 26 de febrero.

- 1965, Documento núm. 2082, presentado al Instituto Autárquico de Colonización y Fomento Rural de Chubut, 12 de noviembre.

, 1991, Decreto Ley de "desregulación pública” núm. 2284, 31 de octubre.

, 1999, Dictamen núm. 93/1999, 27 de julio.

Valtriani, Ana, 2008, Modelos de desarrollo forestal, sus conflictos y perspectivas en el sector de micro pymes forestales. Estudio de caso en la región noroeste y centro de la provincia de Chubut, tesis de doctorado en administración de empresas, Universidad de Buenos Aires-

Facultad de Ciencias Económicas, Buenos Aires.

\section{Entrevistas}

DP, ex trabajador de SAFE y reclamante de su territorio, El Hoyo, 4 de diciembre de 2014.

EB, ex trabajador de manosA, Lago Puelo, junio de 2016.

Elba Pulgar Huentuquidel, El Hoyo, 20 septiembre de 2008.

EP, reclamante de su territorio, El Hoyo, 11 de diciembre de 2013.

Ex empleado de manosa, Lago Puelo, junio de 2016.

Ex funcionarios de la DGByp, Esquel, Chubut, diciembre de 2015 y marzo de 2016.

Ex responsable del Destacamento Epuyén de la DGByp, Esquel, 8 de marzo de 2016 y 21 de marzo de 2017.

Ingeniero forestal, Lago Puelo, junio de 2016

PI, ex trabajador de manoSA y SAFE, Lago Puelo, 10 de marzo de 2015.

vc, ex trabajador de manosa y reclamante de su territorio, Lago Puelo, 7 de abril de 2009.

VL, ex trabajador de SAFE y reclamante de territorio, El Hoyo, 13 de diciembre de 2013. 